\title{
Towards a research agenda for creative tourism: developments, diversity, and dynamics
}

\section{Nancy Duxbury and Greg Richards}

Creative tourism is a niche tourism area that has emerged both as a development of cultural tourism and in opposition to the emergence of 'mass cultural tourism'. While creative tourism is fed by the general growth in cultural tourism, at the same time it caters to people who want more out of their cultural experiences. Creative tourism demand is driven by travellers seeking more active and participative cultural experiences in which they can use and develop their own creativity. Responding to these demands, and in the context of providing alternative approaches to tourism development in many locations, interest in creative tourism is rising internationally.

Although no data are available on the volume of creative tourism, there are some indications of the growth in demand. For example, the percentage of young travellers worldwide indicating that they had used their holidays to develop their creative potential rose from 18 per cent in 2012 to over 30 per cent in 2017 (WYSE Travel Confederation, 2017). Within the cultural tourism market, accounting for just under 40 per cent of all international travel and widely expected to continue growing (UNWTO, 2018), ${ }^{1}$ experience-seeking travel has seen significant growth with an increasing demand for engaging and creative experiences. In Europe, a well-established cultural tourism market, travellers are increasingly interested in discovering new destinations' especially if 'these offer authentic activities that teach them about local culture' (CBI, 2018, n.p.). Altogether, the drive for more engaging culture-based experiences means that the demand for creative tourism is likely to increase in the future.

This volume brings together 30 authors working within and researching creative tourism from different disciplinary perspectives and different origins. Many of these chapters also make strong links between theory and practice. Each chapter provides a window on current investigations in creative tourism, illustrating the variety of research interests, approaches, and geographic contexts informing and influencing the development of the field. Taken together, these cases encapsulate the growing diversity and scope of creative tourism and the expanding body of literature on this topic. From these varied perspectives, we asked each author to suggest future research streams to extend the conceptual questions and pragmatic issues with which they are engaged. 
In this opening chapter, we present an overview of the evolving and diversifying world of creative tourism, discuss the changing contexts for research in this field, and introduce the chapters in this volume. In the closing chapter, we synthesize contributors' suggestions and advice to outline the main research gaps and to elaborate key thematic areas for investigation to advance creative tourism research.

\section{What is creative tourism? An evolving field}

While travel has long been associated with artistic pursuits and creative experiences, in many ways the creative tourism field was launched in $2000^{2}$ when Greg Richards and Crispin Raymond defined creative tourism as:

Tourism which offers visitors the opportunity to develop their creative potential through active participation in courses and learning experiences which are characteristic of the holiday destination where they are undertaken. (p. 18)

This definition corresponds to what can be viewed as creative tourism 1.0 featuring the development of small-scale creative experiences and learning activities, provided mainly by creative entrepreneurs as a supplement to other creative production (Richards, 2015). This type of creative tourism focuses on offering informal, handson workshops and creative experiences and is, in general, production-focused. As Crispin Raymond (2007) describes it, based on his experiences in developing creative tourism in New Zealand, these 'workshops take place in small groups at tutor's homes and places of work; they allow visitors to explore their creativity while getting closer to local people', providing 'an authentic feel for a local culture' and forming the basis of 'a more sustainable form of tourism' (p. 145).

Soon, policies began to be developed related to creative experiences in specific destinations and Internet portals were launched to market and distribute creative tourism (Binkhorst and den Dekker, 2009; Richards and Wilson, 2006), which can be labelled the creative tourism 2.0 phase. This phase reflects a macro consumption-related perspective, with creative activities used to attract tourists to a destination. In this context, in 2006 the United Nations Educational, Scientific and Cultural Organization (UNESCO) Creative Cities Network took up and defined the creative tourism concept as:

Creative tourism is travel directed toward an engaged and authentic experience, with participative learning in the arts, heritage, or special character of a place, and it provides a connection with those who reside in this place and create this living culture. (p. 3)

A variation to this approach linked creative tourism with community-based tourism and community development thinking. For example, in Turismo creativo: el fin de la competitividad (Creative Tourism: The End of Competition), Sergio Molina Espinoza (2011) presented a creative tourism that incorporates development processes focusing on community participation, interests, and expectations, and 
highlights an appreciation of the local culture, environment, and people. In this vision, creative tourism beomes a platform for collaboration among a variety of stakeholders, a process enabled by strategic partners such as public sector institutions, non-governmental organizations (NGOs), and private entrepreneurs. The overall objective is to use tourism as a stimulus to serve the economic and social development of the community, with attention to who is involved in tourism development and to whom the benefits of tourism flow. These ideas continue to resonate internationally, as can be seen in many of the chapters in this volume.

Contextualizing these developments, a shift of focus from tangible resources (e.g., built heritage, museums, monuments, beaches, mountains) to intangible resources (e.g., image, identity, lifestyles, atmosphere, narratives, creativity, media) could be observed in cultural tourism more generally. With a need to develop new types of distinctive cultural tourism, destinations began realizing the growing importance of their symbolic and intangible cultural dimensions (their 'soft cultural infrastructure') in defining their experiential sense of place, promoting their cultural vitality and energy, and as key differentiators in a global tourism marketplace. This focus on intangible cultural resources places people at the heart of cultural tourism, bringing forward important issues of intergenerational cultural sustainability, representation, and intellectual property. It also directs attention to the attractiveness of 'new' creation processes, creative places, and the spirit of creative milieu to tourists.

Consequently, over the past decade, the scope of activities incorporated within the concept of creative tourism has expanded. With the growing presence of the 'creative economy', connections between tourism, creative economy enterprises and activities, and the places they inhabit grew more evident, leading to creative tourism 3.o. This broadening integration of tourism and the creative economy led to the development of a wider range of creative experiences as well as more passive forms of creative consumption by tourists (Long and Morpeth, 2016; OECD, 2014). A growing array of studies of the relationship between tourism and the creative economy examined the development of creative economy policies, specific creative sectors and activities, the role of knowledge and networks in tourism, and the growth of specific creative tourism experiences (e.g., Fahmi et al., 2017; Fernandes, 2011; Gretzel and Jamal, 2009; Richards, 2011; Stolarick et al., 2011; Wattanacharoensil and Schuckert, 2016). Reflecting these development patterns, in a 2014 report for the Organisation for Economic Co-operation and Development (OECD), Tourism and the Creative Economy, Greg Richards re-defined the creative tourism concept to take these trends into account:

Knowledge-based creative activities that link producers, consumers and places by utilising technology, talent or skill to generate meaningful intangible cultural products, creative content and experiences. (p. 7)

Destinations promoting creative experiences are faced with the challenge of fixing relatively mobile creative skills, knowledge, and ideas within their locale. Duxbury 
et al. (forthcoming, 2019) point to the importance of deeply embedding placespecificity in creative tourism activities and experiences, especially in non-urban areas. Growing mobility has also highlighted the importance of networks as 'conduits of knowledge flows and a means to generate creative experiences' (Richards, 2018 , p. 16). This highly networked environment has engendered creative tourism 4.o, characterized by a shift towards 'relational tourism' based on the co-creation of experiences facilitated through peer-to-peer networks (Richards, 2014). This can be viewed as a micro consumption-related perspective blending into prosumption, with tourists designing or co-creating their creative activities and experiences in a particular destination.

It is important to note that while these four types of creative tourism activities developed in a roughly sequential basis, they should be viewed as overlays, with all four dimensions strongly evident today. This also means that what is referred to as 'creative tourism' may be linked to very different types of creative activities and creative contexts, and there is no consistent application of the definitions or terminology relating to creative tourism. A range of definitions have emerged, reflecting different contexts and accenting various dimensions depending on the intentions of the person defining it.

For example, in the CREATOUR research-and-application project (creatour.pt), which focuses on the development of creative tourism in small cities and rural areas in Portugal, the vision of creative tourism is centred on active creative activity encouraging personal self-expression and interaction between visitors and local residents, inspired by local endogenous resources (place and people), and designed and implemented by local residents for community benefit. In reviewing the various definitions of creative tourism that have been published, the CREATOUR team selected four aspects that resonate most strongly with the type of creative tourism activities the project aims to catalyze: active participation, creative self-expression, learning, and a link to the local community. The types of activities developed to date incorporate both workshops (creative tourism 1.0) and more free-form platforms for creative co-creation (creative tourism 4.0).

\section{Researching creative tourism: an emerging field}

As the contexts for creative tourism have diversified and the nature of tourismcreativity connections have evolved and expanded, research has accompanied these developments, providing insights and reflections from a wide variety of local and national contexts. While there is not sufficient space here to review the evolution of this research in detail, in a general way the trajectories of research on creative tourism have moved from identifying the emergence of creativity-based tourism activities, to examining creative tourist motivations and behaviours, the nature of the creative tourism experience, the general forms of organizations supplying creative tourism products, the relationships between tourists and their destination, and the impacts of this activity in the communities in which they occur. Many 
researchers have also worked to bridge their findings and analyses with frameworks for developing new creative tourism initiatives and policies.

The chapters in this volume demonstrate that the field of creative tourism research is much broader than a focus on the creative tourism activity and the experience it offers. Much research remains to be conducted about creative tourists, with a need to better understand both intentional and incidental creative tourists/travellers, and there still is a large gap in our knowledge about the producers of creative tourism offers and experiences. We also observe growing attention to the settings and locales in which these activities take place and how creative tourism initiatives can be strategically designed and levered for both visitor and local benefit. Research on programmes/strategies/policies to frame, inform, nurture, and support creative tourism is rising: ranging from artisan mapping/directories and development programmes, to training and promotional organizations, to strategies for linking creative tourism to local development and planning. A challenge in all this work is to acknowledge and embrace the complementarity of bottom-up innovations and idiosyncratic, unpredictable developments while making room for policy, planning, and collaborative governance frameworks.

At this juncture, we feel it is a timely moment to offer three overarching challenges to researchers. The first challenge is a conceptual one: to build from the prevailing series of definitions of creative tourism and develop a more integrated model. We suggest that defining the field of creative tourism now requires a new framework for organizing the disparate elements that comprise this evolving set of practices, and it may require an integrally dynamic approach, approximating a kaleidoscope perhaps, which would enable the inclusion of an array of types of creative tourism activities and accommodate a wide range of socio-cultural and geographic contexts. Towards this objective, we offer an initial organizing framework that attempts to summarize some of the main aspects of creative tourism development and research (Figure 1.1).

The framework centres on the 'creative core' of creative tourism, which is basically the learning process that is the focus of interactive workshops and creative experiences. These types of activities were the original inspirations for the creative tourism concept, and the idea of involving visitors in the creativity of the destination through learning about local culture, skills, and ideas is still one of the most powerful inspirations for creative tourism development. But the rapid expansion of creative tourism from this original creative tourism 1.0 form has seen a series of new layers added to the field over time. One important dimension of the expansion of creative tourism has been the engagement of visitors as co-creators of their own experiences. This moves away from the formal setting of the workshop, in which the learning environment is usually provided by the producer, to a broader context of creative interaction between local and mobile creatives. In many destinations there is also a trend towards adding creative spectacles as a means of developing more engaging content (Richards and Wilson, 2006). In these settings, which include events, art displays, and architecture, the visitor is basically a passive consumer of 


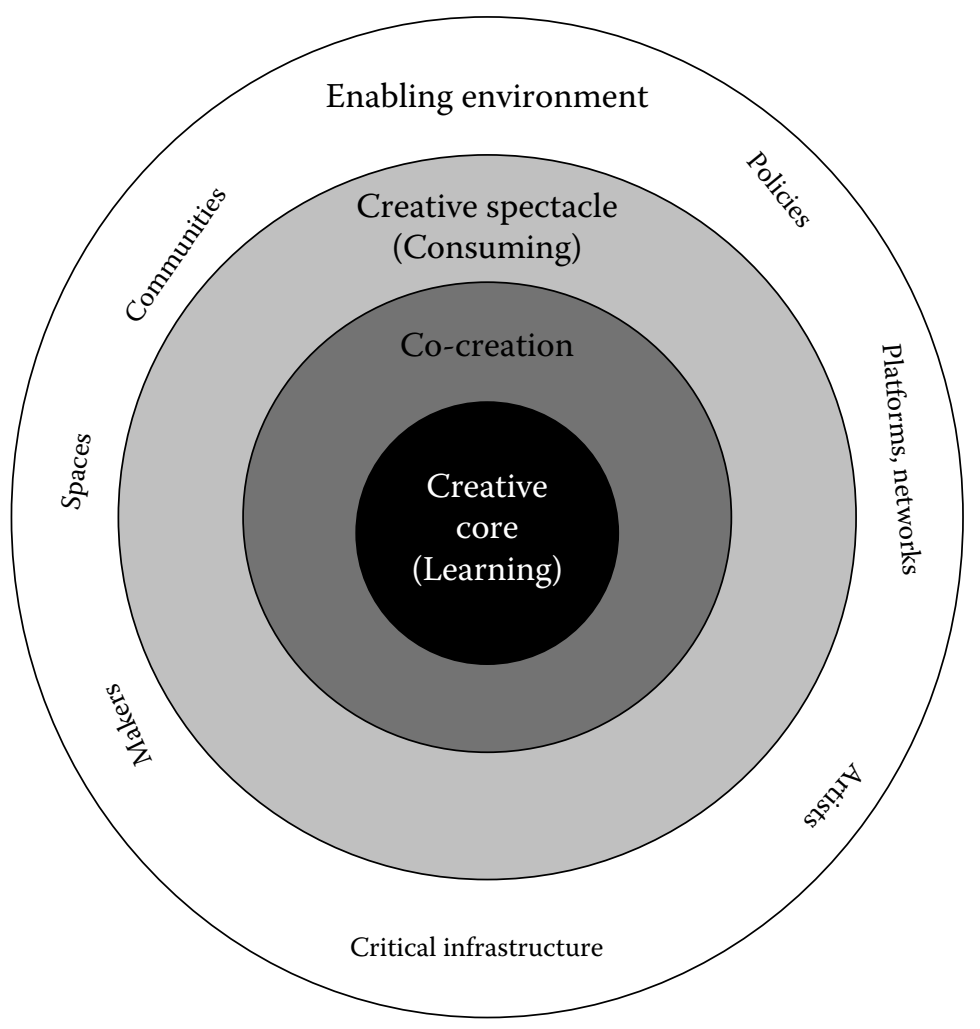

Figure 1.1 The main aspects of creative tourism development and research: an organizing framework

the creativity of others. Finally, creative experiences would not be available without a broad range of creative resources in the local enabling environment. These include creative individuals, communities, and organizations; the spaces and places in which locals and visitors can interact creatively; and the supporting policies for development and marketing. Taken together, the different layers of Figure 1.1 reflect the many different approaches to creative tourism that have emerged over the years, and which are reflected in this volume.

The second challenge is to more explicitly acknowledge and critique the temporal, conceptual, and geographic contexts in which the research and conceptualization in the field has progressed. As creative tourism practices continue to change, the context in which creative tourism is interpreted and understood also evolves. Critically revisiting earlier works in light of situations and challenges today is an important task for the field as it moves forward. For example, when creative tourism was discussed in the early years of the twenty-first century, 'creative cities', 'creative class', and the 'creative economy' were still-emerging ideas that were only beginning to gain notice in policy and planning contexts. Jumping forward to today, we have over 
a decade and a half of experiences, trajectories, and critiques of these topics, and their diffusion in a wide variety of international contexts. How can this work assist us in re-conceiving and critically examining creative tourism trajectories and their impacts? While various notions of creativity remain a strong presence, continuing to influence policy and planning interest in creative tourism as well as some areas of creative tourism research, they share the stage with other societal trends and developments shaping the world today - and travel and tourism within this.

This brings us to the third challenge, to link creative tourism research to the major challenges facing our societies and the planet. As research on creative tourism moves forward, the field should proceed with a heightened cognizance of the significant roles travel and tourism play in constructing and shaping our interconnected world, and the ways in which we imagine and understand it, others, and ourselves. Mitigating the more negative aspects of tourism, for example, in terms of environmental sustainability and in relation to the socio-cultural well-being of in situ communities, could form an important dimension of this. In this context, research could take on a more 'future forming' orientation, to 'bring into focus new and far-reaching potentials of inquiry' (Gergen, 2014, p. 288) and to play an active role in envisioning, informing, and empowering alternatives. Today, we recognize the great need for connections on a human level globally and to our planet, and the essential importance of intercultural learning and sharing experiences. The forces of imagination and creative expression provide us with important tools with which to revitalize and extend cultural traditions and practices, to immerse ourselves in different worldviews and perspectives, and to build renewed visions and pathways for the future, inspiring and informing the world we are collectively constructing. Creative tourism can play an important role in this trajectory going forward.

\section{About this volume}

This volume brings together 30 authors working within and researching creative tourism. Their chapters investigate and reflect on the field of creative tourism and its meaningful articulation in diverse settings:

- World Heritage Sites in Malaysia

- The Indonesian island of Bali

- 13 small communities in Thailand

- Small town 'creative outposts' in British Columbia, Canada

- Community-engaged projects in rural Russia

- The snowy cultural and natural landscape of Lapland, Finland

- Gangneung, Korea's 'coffee city'

- The pioneering creative tourism city of Santa Fe, New Mexico, United States

- A participatory museum in Zagreb, Croatia

- The creative neighbourhoods of Montréal, Canada

- The culture-rich city of Ouro Preto, in the state of Minas Gerais, Brazil

- The virtual landscape of creative tourism networks and platforms. 
The volume is divided into four main parts in which the gaze of the research progressively broadens outward, beginning with research that focuses on the creative tourist and his or her individual experiences; progressing to give greater consideration of the symbiotic relationships between different forms of creative tourism activity and the local contexts in which it occurs: moving on to the challenges of development processes, articulating local impacts, and informing local strategies and policies; and, finally, presenting an international review of the offers of creative tourism platforms and networks that organize and promote creative tourism activities on a collective basis. Following from this array of research perspectives, the volume ends with a concluding chapter that synthesizes and elaborates on the contributors' suggested future research trajectories in creative tourism.

Part I: The Creative Tourist and Creative Tourism Experiences presents three chapters focused on understanding the creative tourist and examining core elements of the creative tourism experience: taking creative action, authenticity, and emotions.

Siow-Kian Tan and Siow-Hooi Tan's chapter, 'Nurturing the creative tourist in Malaysia', is based on in-depth interviews and observations at George Town and Melaka, Malaysia's World Heritage Sites. It aims to identify possible routes that could be used to encourage creative tourists, particularly at such heritage sites. Informed by literature on the formative influences of awareness/consciousness, social justice concerns, and sense of place, they search for the keys that motivate people to move beyond awareness to take the actions that are vital for a creative experience. The study aims to examine how awareness, creativity, and actionoriented knowledge - all vital for nurturing creative tourists - can be applied to learning processes related to intrapersonal and development aspects of creativity, a gap in the research to date. They then turn to analyze the different stakeholders involved in heritage sites, examine how they could play a role in nurturing creative tourists, and identify some challenges and barriers to encouraging creative tourism in this context.

Authenticity is often presented as a key element of creative tourism but is often incorporated in an uncritical manner. In 'The role of authenticity in rural creative tourism', Manuela Blapp and Ondrej Mitas critically examine the role of authenticity in creative tourism in rural areas of the Indonesian island of Bali. They argue that to develop creative tourism in rural areas and prevent commodification, the theoretical assumptions and definitions behind ideas of authenticity must be carefully considered. Extending the discussion in the literature on this topic, their chapter analyzes how different theories of authenticity are applied in creative and community-based tourism literature and suggests a synthetic theory of authenticity applicable to creative tourism development in rural areas. This theory is explored in the context of five Balinese villages using a microethnographic approach with participant observation and expert as well as tourist interviews.

Daniela Angelina Jelinčić and Matea Senkić's chapter, 'The value of experience in culture and tourism: the power of emotions', seeks strategies to design meaningful 
experiences into cultural and creative tourism attractions and activities. Looking to research on the experience economy, the authors find that meaningful experiences are based on creating different innovative, spectacular, and sensory stimuli that engage tourists to identify with them and/or to participate and co-create. In other words, to achieve a 'real' response in a tourism experience, it is necessary to stimulate emotions with which tourists are able to identify. As Jelinčić and Senkić elaborate, tourists increasingly seek experiences that reflect their own personal stories, and successful experience creation must include this personal identification with the attraction. The chapter provides a transdisciplinary theoretical background on experience creation drawing from the fields of psychology, culture, and tourism to introduce the concept of tourist emotional engagement. The authors examine this concept in the context of an experience co-(re)creation exhibit within the Museum of Broken Relationships, in Zagreb, Croatia. The authors contend that since emotions instigate response behaviours, a participatory creative activity such as writing personal experiences (as integrated into this exhibit) can provide an experience for self-healing and transformation.

In Part II: Forms of Creative Tourism Destinations, four types of creative tourism initiatives are presented in very different settings, with research that investigates and reflects on the interaction between creative tourism activities, the places that inform, inspire, and nurture these experiences, and local dynamics that may be catalyzed in these creative tourism experiences.

Patrick Brouder's chapter, 'Creative tourism in creative outposts', focuses on the subtle, yet palpable, role of creative processes that contribute to rural peripheral tourism innovation and regional development. Creative outposts are defined as rural peripheral communities that face challenging socio-economic environments but meet these challenges by deploying endogenous creative capital resulting in a palpable shift towards a more sustainable socio-economic environment. As Brouder observes, the 'island-like' status of these outpost communities opens up both the possibility for and the challenge of increased local interaction and cooperation. He argues that tourism has proven to be tenacious in rural peripheral areas and that creative tourism has a clear role in the long-term resilience of rural communities. In order to illustrate the challenge of, and the necessity for, understanding the potential of creative tourism in creative outposts, three cases from rural British Columbia, Canada (Ashcroft, Fernie, and Salt Spring Island) are presented.

In 'Stories of design, snow, and silence: creative tourism landscape in Lapland', Satu Miettinen, Jaana Erkkilä-Hill, Salla-Mari Koistinen, Timo Jokela, and Mirja Hiltunen discuss how the creative tourism landscape in Lapland has been constructed and transformed into a topography of artistic collaboration, walking, and gazing. They introduce Arctic design and artistic production as creative contexts that allow people to both participate and develop a cluster of events aimed at increasing art, creativity, and innovation in the Arctic. Three case studies are presented. The first case study, 'Lapland Snow Art and Design', represents snow and ice forming the landscape and location for artistic production and tourist activity. 
The second case study, 'Travelling Laboratories for Artistic Thinking', studies the artist's way of producing a tourism experience through performance and mediation in silence and walking. The third case study, 'Master's degree programme of Applied Visual Arts and Nature Photography', introduces a contemporary discussion on creating the tourist gaze in the Arctic through photography. The case studies are analyzed using art education as an embodied practice and in terms of collaborative design processes in creative tourism. The chapter discusses active engagement and ways of introducing creative and cultural activities as tools for collaboration between tourists and local communities, and the positioning of community members as visitors in their own topography.

U-Seok Seo's chapter, 'Coffee tourism as creative tourism: implications from Gangneung's experiences', discusses the diverse relationships between creativity and coffee tourism in Gangneung, South Korea. The chapter outlines how the rise of coffee tourism has been possible in a small city such as Gangneung and how the city's use of creativity contributed to this achievement. Coffee tourism in Gangneung provides creative tourism opportunities like learning various knowledges about coffee and participating in a variety of coffee-related DIY experiences. The author suggests a more differentiated understanding of creative tourism is needed to understand a variety of these creative tourism developments (such as a 'snack culture' type). Creative spaces have been made in cafés, which function as cultural spaces, with some linked to popular media and visiting celebrities. The creative convergence evident in Gangneung's experiences means coffee tourism now plays a pivotal role in fostering favourable circumstances for culture-based urban regeneration through attracting taste-oriented visitors and enhancing place image.

Closing this part, Marie-Andrée Delisle's chapter, 'Montréal: a creative tourism destination?', challenges the assumption that creative tourism initiatives are a 'natural' aspect of the life of a well-known 'creative city'. Her research finds that although widely considered a 'creative' destination, Montréal somehow has not invested in creative tourism. She points to the intense programming of the 375th anniversary of the city in 2017 as an opportunity for its population to participate directly in imagining the city in a creative way and to actively engage in the celebration of their city at a community level - an event-based decentralized platform that also helped facilitate the immersion of visitors in the local culture and way of life. She asks: From this base, how can creative tourism be fostered in the city? The research conducted for this chapter found that artists and artisans may not be aware of the opportunity available for them to offer creative workshops to visitors. There are numerous workshops already offered to the local population, so adapting those for visitors may represent an easy transfer, but one would need to motivate the artists and artisans into extending their activities as workshop productions for visitors, and the process would have to be facilitated. Various examples and some interviews with key stakeholders illustrate these topics. In closing, the chapter suggests seeds for the implementation of creative tourism workshops in Montréal's neighbourhoods. 
Part III: Creative Tourism in Local Development turns to examination of development models and processes and addresses the issue of how to measure and monitor the multidimensional impacts of creative tourism on local communities.

Brent Hanifl begins this part with the chapter 'Creative tourism in Santa Fe, New Mexico', which provides an overview of the development of a major, pioneering creative tourism initiative in the United States. Hanifl then discusses research undertaken to identify the economic value of 'creative tourism' activity in Santa $\mathrm{Fe}$, including efforts to assess the scope, nature, and extent of creative tourism activities and to identify and assess the economic value of creative tourism in the city. Hanifl describes efforts to evaluate the characteristics of a thriving arts and culture sector to support creative tourism activities, and raises the important issue of directing investments in creative tourism towards developing activities of interest to creative tourists versus investments to brand a place as a creative tourism destination.

In 'Local impacts of creative tourism initiatives', Jutamas (Jan) Wisansing and Thanakarn (Bella) Vongvisitsin present an integrated monitoring system called 'Linkages and Leakages' which has been developed combining the lessons learned from a pilot project in six designated areas in Thailand with a synthesis of extensive information on impact evaluations and indicators applicable to measuring various aspects of social, economic, and environmental sustainability at a community level. The resulting Community Benefitting through Creative Tourism (CBCT) model maps out impacts and benefits from end to end across the entire creative tourism value chain. This comprehensive and local-friendly tool was leveraged by a multistakeholders' co-creation and facilitated by the Designated Areas for Sustainable Tourism Administration (DASTA). It has been designed as a locally owned and led process for monitoring, managing, and enhancing the sustainability of creative tourism initiatives. Three intertwined sustainable dimensions - articulating an ecologically, socio-culturally, and economically sustainable and equitable environment - enable community leaders to delineate the need for empowerment and capacitybuilding programmes, local sourcing strategies, and starting up community enterprises and their social capital-building structures (social networks and trust).

Marina Matetskaya, Alexandra Svyatunenko, and Olga Gracheva's chapter, 'The development of creative tourism in rural areas of Russia: issues of entrepreneurial ability, cooperation, and social inclusion', examines the experience of several projects initiated by NGOs that aim to support the initiatives of local residents in the field of rural creative tourism. The chapter highlights the particular characteristics and features of rural areas that make rural tourism initiatives differ from those of city tourism. Along with governmental support measures and private investments, the authors contend that rural projects have a number of advantages in terms of collaborating with local communities, including craftspeople/artisans, who present a specific category of business unit. Combining a literature review with case study research, Matetskaya, Svyatunenko, and Gracheva discuss management tools employed by tourism projects in rural areas, approaches to community engagement 
in tourism-related projects, and creative tourism models and challenges in rural areas.

Closing this part, and linking creative tourism to local policy development in an urban context, Magnus Luiz Emmendoerfer's chapter, 'Creative tourist regions as a basis for public policy', presents the concept of 'creative tourist regions' to support the elaboration and implementation of public policies in support of creative tourism at the municipal level, drawing from case study research in Ouro Preto, Brazil. Informed by comparisons between the concepts of creative tourism and community-based tourism, as well as ideas from creative economy and public policy, the idea of the creative tourist region is elaborated as the basis for public policy that respects and congregates the diversity of existing cultural and market expressions in an area and represents it with an intent to induce tourism. Emmendoerfer also proposes elements that can help plan and monitor local public policies in regards to both tourism activities and creative ventures. Attention to collective actions among stakeholders and collaborative governance underpin this work.

Part IV: Creative Tourism Networks and Platforms presents the initial findings of an international examination of creative tourism networks and platforms. As mentioned earlier, many of these networks were established to profile and promote creative tourism to attract tourists to a specific destination (local, regionally, or nationally defined) but these organizations have not been systematically examined. In 'Good and not-so-good practices in creative tourism networks and platforms: an international review', Paula Remoaldo, Olga Matos, Isabel Freitas, Hélder da Silva Lopes, Vítor Ribeiro, Ricardo Gôja, and Miguel Pereira report on the first systematic international review of these organizations and structures, conducted within the framework of the CREATOUR project. This chapter reports the primary findings of an investigation of the websites of these networks and platforms, carried out in 2017 , to identify and analyze existing practices and initiatives undertaken by each institution. The study reinforces our observations that a consensus has not yet been reached worldwide regarding the concept of creative tourism. The main results show that not all initiatives referred to as 'creative experiences' have identifiable creative content or focus. The fact that most of the identified initiatives stem from southern Europe also suggests that many are driven by a desire to diversify tourism, rather than to develop creativity per se.

In the closing chapter of this volume, 'Towards a research agenda in creative tourism: a synthesis of suggested future research trajectories', Nancy Duxbury and Greg Richards provide an overview of the main themes for future research that have been suggested in this volume and point out potentially fruitful future research avenues within the tourism field and related to it. The chapter is organized into nine thematic areas: the creative tourist, creative tourism experiences, creative supply, marketing creative tourism, the development of creative tourism experiences and destinations, assessing creative tourism development, the role of local communities in creative tourism, placemaking through creative tourism, and creative tourism networks and platforms. 


\section{NOTES}

1 According to an August 2017 report from London-based market research forecasters Technavio, the global cultural tourism market is expected to grow at a compound annual growth rate of almost 36 per cent between 2017 and 2021, and will be valued at US\$10.02 trillion by 2021 .

2 Richards (2010) outlines the genesis of the creative tourism concept. He notes that the idea arose in the mid-1990s within the EUROTEX project when a group of researchers and practitioners were looking at ways to enhance the sales of craft products to tourists: "Through discussions with craft producers and interviews with tourists, we quickly realised that many visitors were interested in seeing how craft products were made, and many wanted to learn craft skills for themselves. As a result, we decided to develop craft experiences which allowed the visitors to get involved with the production process, either by seeing craft producers at work or by learning particular textile production techniques' (p. 79). These ideas became the inspiration for what would be called creative tourism.

\section{References}

Binkhorst, E. and T. den Dekker (2009), 'Agenda for co-creation tourism experience research', Journal of Hospitality Marketing and Management, 18 (2-3), 311-27.

CBI, UK Ministry of Foreign Affairs (2018), What are the Opportunities for Cultural Tourism from Europe?, accessed 13 October 2018 at https://www.cbi.eu/marketinformation/tourism/culturaltouri sm/culturaltourismeurope/.

Duxbury, N., S. Silva and T.V. de Castro (forthcoming, 2019), 'Creative tourism development in small cities and rural areas in Portugal: insights from start-up activities', in D.A. Jelinčić and Y. Mansfeld (eds), Creating and Managing Experiences in Cultural Tourism, Singapore: World Scientific Publishing.

Fahmi, F.Z., P. McCann and S. Koster (2017), 'Creative economy policy in developing countries: the case of Indonesia', Urban Studies, 54 (6), 1367-84.

Fernandes, C. (2011), 'Cultural planning and creative tourism in an emerging tourist destination', International Journal of Management Cases, 13 (3), 629-36.

Gergen, K.J. (2014), 'From mirroring to world-making: research as future forming', Journal for the Theory of Social Behaviour, 45 (3), 287-310. doi:10.1111/jtsb.12075.

Gretzel, U. and T. Jamal (2009), 'Conceptualizing the creative tourist class: technology, mobility, and tourism experiences', Tourism Analysis, 14 (4), 471-81.

Long, P. and N.D. Morpeth (2016), Tourism and the Creative Industries: Theories, Policies and Practice, London: Routledge.

Molina Espinoza, S. (2011), Turismo creativo: el fin de la competitividad (Creative Tourism: The End of Competition), Santiago, Chile: Escritores.

OECD (2014), Tourism and the Creative Economy, Paris: OECD.

Raymond, C. (2007), 'Creative Tourism New Zealand: the practical challenges of developing creative tourism', in G. Richards and J. Wilson (eds), Tourism, Creativity and Development, London: Routledge, pp. 145-57.

Richards, G. (2010), 'Creative tourism and local development', in R. Wurzburger, T. Aageson, A. Pattakos and S. Pratt (eds), Creative Tourism: A Global Conversation, Santa Fe, NM: The City of Santa Fe, pp. 78-90.

Richards, G. (2011), 'Creativity and tourism: the state of the art', Annals of Tourism Research, 38 (4), 1225-53.

Richards, G. (2014), 'Creativity and tourism in the city', Current Issues in Tourism, 17 (2), 119-44.

Richards, G. (ed.) (2015), Creative Tourism Trend Report Volume 1, Arnhem: ATLAS.

Richards, G. (2018), 'Cultural tourism: a review of recent research and trends', Journal of Hospitality and Tourism Management, 36, 12-21.

Richards, G. and C. Raymond (200o), 'Creative tourism', ATLAS News, no. 23, 16-20. 
Richards, G. and J. Wilson (2006), 'Developing creativity in tourist experiences: a solution to the serial reproduction of culture?', Tourism Management, 27, 1209-23.

Stolarick, K.M., M. Denstedt, B. Donald and G.M. Spencer (2011), 'Creativity, tourism and economic development in a rural context: the case of Prince Edward County', Journal of Rural and Community Development, 5 (1-2), 238-54.

Technavio (2017), Global Cultural Tourism Market 2017-2021, Toronto: Technavio.

UNESCO Creative Cities Network (2006), Towards Sustainable Strategies for Creative Tourism. Discussion Report of the Planning Meeting for 2008 International Conference on Creative Tourism, Santa Fe, New Mexico, U.S.A., October 25-27, 2006, accessed 16 October 2018 at http://unesdoc. unesco.org/images/oo15/o01598/159811e.pdf.

UNWTO (2018), Report on Tourism and Culture Synergies, Madrid: UNWTO.

Wattanacharoensil, W. and M. Schuckert (2016), 'Reviewing Thailand's master plans and policies: implications for creative tourism?', Current Issues in Tourism, 19 (10), 1045-70.

WYSE Travel Confederation (2017), New Horizons, Preliminary Results, Paris: UNWTO and UNESCO. 